H. C. Gerstein - J. Pogue - J. F. E. Mann - E. Lonn •

G. R. Dagenais $\cdot$ M. McQueen $\cdot$ S. Yusuf •

HOPE investigators

\title{
The relationship between dysglycaemia and cardiovascular and renal risk in diabetic and non-diabetic participants in the HOPE study: a prospective epidemiological analysis
}

Received: 8 November 2004 / Accepted: 28 April 2005 / Published online: 30 July 2005

(C) Springer-Verlag 2005

\begin{abstract}
Aims/hypothesis: Emerging data suggest that different indices of glycaemia are risk factors for clinical events. The aim of this analysis was to investigate the relationship between fasting plasma glucose or glycated haemoglobin $(\mathrm{GHb})$ levels and incident cardiovascular (CV) outcomes, death, heart failure and overt nephropathy in diabetic and non-diabetic individuals enrolled in the Heart Outcomes Prevention Evaluation (HOPE) study. Materials and methods: The adjusted 4.5-year risk of CV events (myocardial infarction or stroke or CV death), heart failure, death and overt nephropathy was analysed in relation to baseline and updated $\mathrm{GHb}$ levels (in 3,529 diabetic HOPE study participants) and baseline fasting plasma glucose levels (in 1,937 non-diabetic and 1,013 diabetic participants). Results: In diabetic participants, a $1 \%$ absolute rise in the updated $\mathrm{GHb}$ predicted future $\mathrm{CV}$ events (relative risk $[\mathrm{RR}]=1.07,95 \%$ CI $1.01-1.13 ; p=0.014)$, death $(\mathrm{RR}=1.12$, $95 \%$ CI $1.05-1.19 ; p=0.0004)$, heart failure $(\mathrm{RR}=1.20,95 \%$ CI $1.08-1.33 ; p=0.0008)$ and overt nephropathy $(\mathrm{RR}=1.26$,
\end{abstract}

Listed by country in References 13 and 15 .

H. C. Gerstein · J. Pogue $\cdot$ E. Lonn · M. McQueen · S. Yusuf McMaster University and the Population Health

Research Institute,

Hamilton, Ontario, Canada

J. F. E. Mann

Schwabing Clinical Centre,

Ludwig Maximilians University,

Munich, Germany

G. R. Dagenais

Laval University Heart and Lung Institute,

Ste-Foy, Quebec, Canada

H. C. Gerstein $(\bowtie)$

Department of Medicine,

McMaster University and the

Population Health Research Institute,

Room 3V38, 1200 Main Street West,

Hamilton, Ontario, L8N 3Z5, Canada

e-mail: gerstein@mcmaster.ca

Tel.: +1-905-5212100

Fax: +1-905-5214971
95\% CI 1.17-1.36; $p<0.0001)$ after adjusting for age, sex, diabetes duration, blood pressure, WHR, hyperlipidaemia and ramipril. Similarly, a $1 \mathrm{mmol} / 1$ rise in fasting plasma glucose was related to an increased risk of $\mathrm{CV}$ outcomes $(\mathrm{RR}=1.09,95 \%$ CI $1.05-1.13 ; p<0.0001)$, death $(\mathrm{RR}=1.06$, $95 \% \mathrm{CI} 1.01-1.12 ; p=0.017)$, heart failure $(\mathrm{RR}=1.16,95 \% \mathrm{CI}$ $1.06-1.13 ; p=0.0007)$ and overt nephropathy $(\mathrm{RR}=1.34,95 \%$ CI 1.23-1.45; $p<0.0001)$ in the group composed of diabetic and non-diabetic individuals. The significant relationship between fasting plasma glucose and CV outcomes persisted after adjustment for diabetes status (RR $=1.06,95 \%$ CI 1.00 $1.12 ; p=0.043)$. Conclusions/interpretation: There is an independent progressive relationship between indices of glycaemia and incident CV events, renal disease and death. Clinical trials of glucose lowering to prevent these outcomes in diabetic and non-diabetic individuals are indicated.

Keywords Cardiovascular diseases - Diabetes - Diabetic nephropathy $\cdot$ Dysglycaemia $\cdot$ Renal $\cdot$ Risk

Abbreviations CV: cardiovascular - GHb: glycated haemoglobin - HOPE: Heart Outcomes Prevention Evaluation $\cdot R R$ : relative risk

\section{Introduction}

Diabetes mellitus is universally recognised as a strong, independent risk factor for cardiovascular (CV) events [1]. Compared with non-diabetic individuals, those with diabetes are two to three times more likely to have a CV event; moreover, the proportion of people with diabetes who will die from cardiovascular causes is $>70 \%$ [2]. Epidemiological and mechanistic explanations that have been proposed to account for this strong relationship include: (1) prolonged exposure to hyperglycaemia and its consequences [3]; (2) antecedent and concurrent insulin resistance $[4,5]$; (3) effective insulin deficiency [6]; (4) associated lipid and blood pressure abnormalities [7]; and (5) an as yet undefined determinant of both diabetes and CV disease. Varying proportions of individuals with diabetes manifest one or 
more of these abnormalities; however, as diabetes is defined on the basis of an elevated glucose level, everyone with diabetes has a history of hyperglycaemia. This has focused attention on the role of the plasma glucose level as a potential risk factor for $\mathrm{CV}$ events and atherosclerosis in both diabetic and non-diabetic individuals [8-10].

A growing body of epidemiological evidence now supports the possibility that the degree of dysglycaemia, as measured by either the glucose level or the $\mathrm{HbA}_{1} \mathrm{c}$ level, is an independent risk factor for CV events [11]. Moreover, this relationship has been observed in people with and without evidence of diabetes $[8,9,12]$. What remains unclear is the degree to which the CV risk attributable to diabetes is explained by the elevated glucose level [13]. It is also unknown whether the glucose-CV risk relationship can be accounted for by a link between glucose and other $\mathrm{CV}$ risk factors such as hypertension, hyperlipidaemia and abdominal obesity.

The Heart Outcomes Prevention Evaluation (HOPE) study was an international 4.5 -year multicentre trial that showed that the ACE inhibitor ramipril reduced the risk of $\mathrm{CV}$ events in a broad spectrum of diabetic and non-diabetic high-risk participants [14]. Individuals with diabetes were required to have a locally measured glycated haemoglobin $(\mathrm{GHb})$ level at baseline and annually throughout the study. In addition, a baseline fasting serum sample was collected in 3,196 diabetic and non-diabetic individuals who were enrolled within Canada. These data provide an opportunity to assess the epidemiological relationship between $\mathrm{GHb}$, fasting plasma glucose and CV outcomes in individuals with and without diabetes.

\section{Subjects and methods}

\section{Participants}

The HOPE study randomly allocated people at high risk of cardiovascular events to receive $10 \mathrm{mg}$ of ramipril or placebo daily, and/or $400 \mathrm{IU}$ of vitamin E or placebo daily using a factorial design. A total of 9,541 people $(3,577$ with self-reported diabetes at baseline) were recruited within 19 countries and were followed every 6 months for a median of 4.5 years for the development of study outcomes. The HOPE study was approved at each centre by the local ethics committee and all participants provided written informed consent.

$\mathrm{GHb}$ was measured in all participants with self-reported diabetes (in each study centre's local laboratory) as either total $\mathrm{GHb}$ or $\mathrm{HbA}_{1} \mathrm{c}$. The results of baseline and annual measurements were recorded throughout the study as an assessment of diabetes control. Investigators were not asked to measure or record $\mathrm{GHb}$ levels in participants without a history of diabetes. Fasting venous blood samples from the diabetic and non-diabetic participants who were recruited in Canadian sites were collected at baseline, frozen, and then stored centrally in liquid nitrogen for subsequent analyses. This report focuses on the relationship of $\mathrm{GHb}$ (in all participants with diabetes) and fasting plasma glucose (in the
Canadian diabetic and non-diabetic participants) with the incident key study outcomes.

Assessment of glycaemia and other risk factors

Both the measured $\mathrm{GHb}$ result and the upper limit of normal for the assay used were recorded whenever $\mathrm{GHb}$ was measured. The $\mathrm{GHb}$ results were then expressed and analysed as a 'derived $\mathrm{HbA}_{1} \mathrm{c}$ ' based on an assay with an upper limit of normal of $6.0 \%$, which was calculated as: (local measured result/local upper limit) $\times 6 \%$. Fasting plasma glucose was measured on stored plasma in the central laboratory using a glucose oxidase method (Integra; Roche Diagnostics, Basel, Switzerland), and total cholesterol and HDL cholesterol were measured on centrally stored plasma using an enzymatic, colorimetric method (Integra; Roche Diagnostics). Albuminuria was measured in four central laboratories around the world, as previously reported $[15,16]$. Participants were deemed to have a history of hyperlipidaemia if a recent total cholesterol was $>5.2 \mathrm{mmol} / \mathrm{l}$, a recent HDL cholesterol was $<0.9 \mathrm{mmol} / \mathrm{l}$, or if they were taking lipid-lowering medication.

\section{Outcomes analysed}

The definitions of the key outcomes measured in the HOPE study and Microalbuminuria, Cardiovascular, and Renal Outcomes in HOPE (MICRO-HOPE) substudy have been published previously in detail $[14,17]$. Briefly, the primary outcome was the first occurrence of one or more of the following: non-fatal myocardial infarction, stroke or CV death. Key secondary outcomes included total mortality, hospitalisation for congestive heart failure, overt nephropathy (i.e. measured as clinical proteinuria) and each component of the composite primary outcome. Participants were assessed for the development of overt nephropathy at baseline and study end; diabetic participants were also assessed for this outcome at 1 year. Overt nephropathy was defined as a urinary AER $\geq 300 \mathrm{mg} /$ day or $200 \mu \mathrm{g} / \mathrm{min}$; a urinary protein excretion rate $\geq 500 \mathrm{mg} / \mathrm{day}$; or (in the absence of a timed collection) a first morning urine albumin : creatinine ratio $>36 \mathrm{mg} / \mathrm{mmol}$.

\section{Statistical analyses}

Two groups of participants were analysed: (1) all diabetic participants with $\mathrm{GHb}$ measurements; and (2) diabetic and non-diabetic participants for whom fasting baseline blood was stored (i.e. those who were enrolled in Canada) and later assayed for plasma glucose ( $\mathrm{GHb}$ levels were not measured in the non-diabetic participants).

During the course of the trial, updated GHb levels were calculated for each diabetic individual as the mean of all of the available measurements for that individual during the entire period of follow-up. Any individual for whom there was one or more $\mathrm{GHb}$ value was included in this analysis, 
regardless of the number of available GHb levels that contributed to the updated number.

The relationship between $\mathrm{GHb}$ and the risk of outcomes in diabetic participants was analysed by relating the incidence of an event to two different assessments of $\mathrm{GHb}$ : the baseline level and the updated level. GHb was assessed as a categorical variable (i.e. according to each decile of the distribution) and as a continuous variable. Cox regression models were used to estimate the covariate-adjusted relative hazard for each event within each decile of $\mathrm{GHb}$ and for a $1 \%$ rise in $\mathrm{GHb}$. The relationship between baseline fasting plasma glucose (according to each quintile of glucose and as a continuous variable) and the risk of outcomes in diabetic and non-diabetic participants was analysed using a similar approach. A $p$ value of less than 0.05 was considered significant.

\section{Results}

A locally measured baseline $\mathrm{GHb}$ level was available for $3,529(98.7 \%)$ of the 3,577 participants with a history of diabetes, and a centrally measured fasting plasma glucose level was available for 2,950 (92.3\%) of the 3,196 nondiabetic $(n=1,937)$ and diabetic $(n=1,013)$ participants for whom a baseline serum sample was stored. Baseline biochemical and clinical data for each of these two groups are listed in Table 1.

$\mathrm{GHb}$ and incident $\mathrm{CV}$ and renal outcomes in diabetes

There was a consistent and progressive relationship between the GHb level (both baseline and updated) and the age- and sex-adjusted relative hazard of the following outcomes: (1) the primary outcome; (2) hospitalisation for congestive heart failure; (3) total mortality; and (4) overt nephropathy (Fig. 1). The strongest relationships were seen with the updated $\mathrm{GHb}$ level. After adjusting for age, sex, diabetes duration, systolic and diastolic blood pressure, WHR, history of hyperlipidaemia, and randomisation to ramipril, a $1 \%$ rise in the updated $\mathrm{GHb}$ level was associated with a $7 \%$ rise in the risk of the primary outcome, a $20 \%$ rise in the risk of hospitalisation for heart failure, a $12 \%$ rise in the risk of total mortality, and a $26 \%$ rise in the risk of overt nephropathy (Table 2).

Fasting plasma glucose and incident CVD and renal outcomes

A similar relationship was seen between baseline fasting plasma glucose and the age- and sex-adjusted risk of each of the outcomes (Fig. 2). Moreover, after adjusting for age, sex, systolic and diastolic blood pressure, WHR, history of hyperlipidaemia, and allocation to ramipril, a 0.15 -unit rise in baseline log fasting plasma glucose (equivalent to an increment in fasting plasma glucose of approximately $1 \mathrm{mmol} / \mathrm{l}$ ) was associated with a $9 \%$ rise in the risk of the primary outcome, a $16 \%$ rise in the risk of hospitalisation for heart failure, a $6 \%$ rise in the risk of total mortality and a $34 \%$ rise in the risk of overt nephropathy (Table 3).Similar results were noted when hyperlipidaemia wasreplaced in the model by the fasting cholesterol:HDL cholesterol ratio and the triglyceride level (Table 3 ). The significant relationship between fasting plasma glucose and the primary outcome (but not the other outcomes) was retained after adjustment for the presence of diabetes (relative risk $[\mathrm{RR}]=1.06$; 95\% CI 1.00-1.12; $p=0.043$ ).
Table 1 Baseline characteristics of the participants

${ }^{\mathrm{a} C}$ Continuous variables are reported as means \pm SD and categorical variables are reported as percentages

${ }^{\mathrm{b}}$ In people with baseline diabetes

${ }^{\mathrm{c}}$ In people with blood samples stored at baseline

\begin{tabular}{|c|c|c|c|c|}
\hline \multirow[t]{2}{*}{ Characteristic } & \multicolumn{2}{|c|}{$\begin{array}{l}\text { Diabetic participants } \\
\text { with a baseline } \mathrm{GHb}\end{array}$} & \multicolumn{2}{|c|}{$\begin{array}{l}\text { Diabetic and non-diabetic } \\
\text { participants with a baseline fasting } \\
\text { plasma glucose }\end{array}$} \\
\hline & $n$ & Value $^{\mathrm{a}}$ & $n$ & Value $^{a}$ \\
\hline Mean age (years) & 3,529 & $65.4 \pm 6.5$ & 2,950 & $65.4 \pm 6.5$ \\
\hline Females & 1,291 & 36.6 & 647 & 21.9 \\
\hline Hyperlipidaemia & 2,460 & 69.7 & 1,984 & 67.3 \\
\hline On lipid therapy & 786 & 22.3 & 917 & 31.1 \\
\hline Systolic BP (mmHg) & 3,528 & $142.4 \pm 19.5$ & 2,950 & $136.2 \pm 18.6$ \\
\hline Diastolic BP (mmHg) & 3,528 & $79.9 \pm 10.5$ & 2,950 & $77.4 \pm 9.7$ \\
\hline Mean WHR & 3,523 & $0.93 \pm 0.08$ & 2,950 & $0.93 \pm 0.08$ \\
\hline Diabetes & 3,529 & 100 & 1,013 & 34.3 \\
\hline Diabetes duration (years) ${ }^{b}$ & 3,442 & $11.46 \pm 10.5$ & 1,008 & $10.34 \pm 9.4$ \\
\hline Mean GHb $(\%)^{b}$ & 3,529 & $7.40 \pm 1.87$ & 1,014 & $7.35 \pm 1.85$ \\
\hline Follow-up GHb available & 3,292 & 93.3 & 1,084 & 36.8 \\
\hline Mean fasting plasma glucose $(\mathrm{mmol} / \mathrm{l})^{\mathrm{c}}$ & 1,013 & $9.33 \pm 3.18$ & 2,950 & $6.87 \pm 2.71$ \\
\hline Mean cholesterol (mmol/l) & 1,014 & $5.47 \pm 1.07$ & 2,950 & $5.49 \pm 1.01$ \\
\hline Mean HDL cholesterol (mmol/l) & 1,013 & $1.03 \pm 0.28$ & 2,949 & $1.06 \pm 0.28$ \\
\hline Mean cholesterol:HDL cholesterol ratio & 1,013 & $5.66 \pm 1.76$ & 2,949 & $5.51 \pm 1.65$ \\
\hline Triglyceride $(\mathrm{mmol} / \mathrm{l})$ & 1,014 & $2.47 \pm 1.58$ & 2,950 & $2.22 \pm 1.27$ \\
\hline
\end{tabular}


a

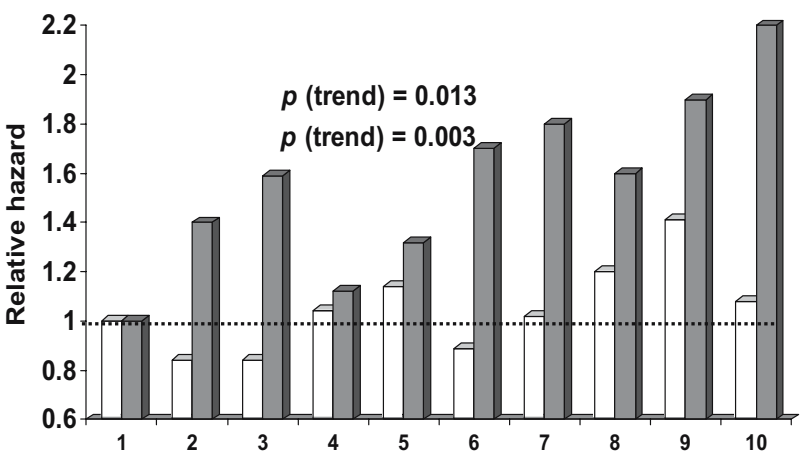

C

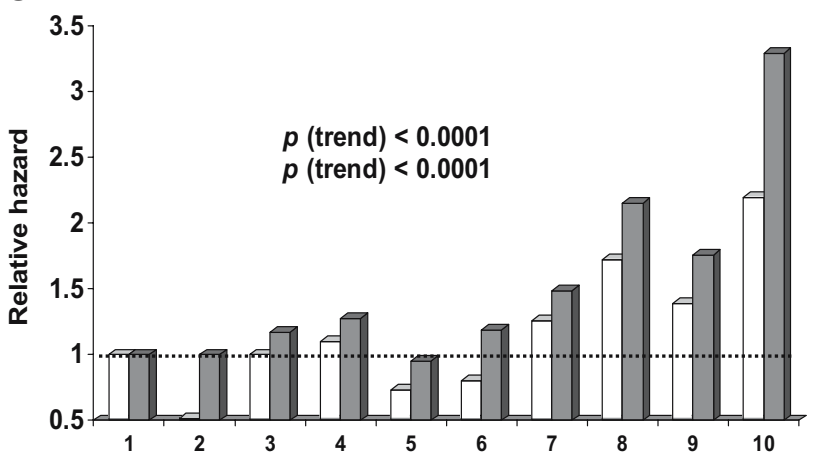

b

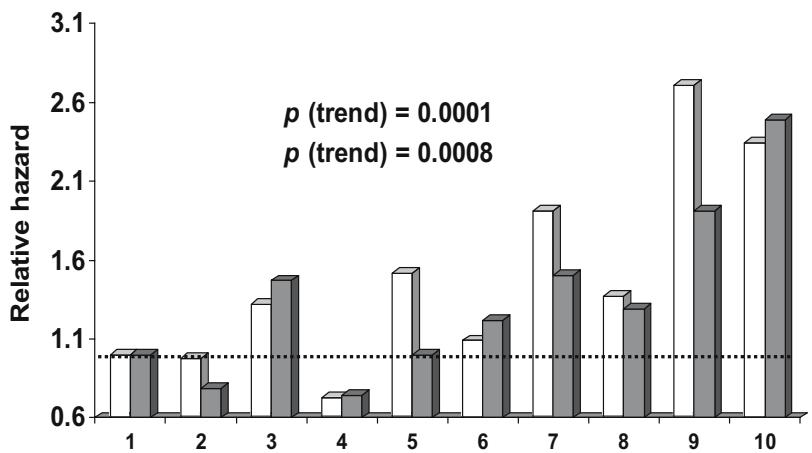

d

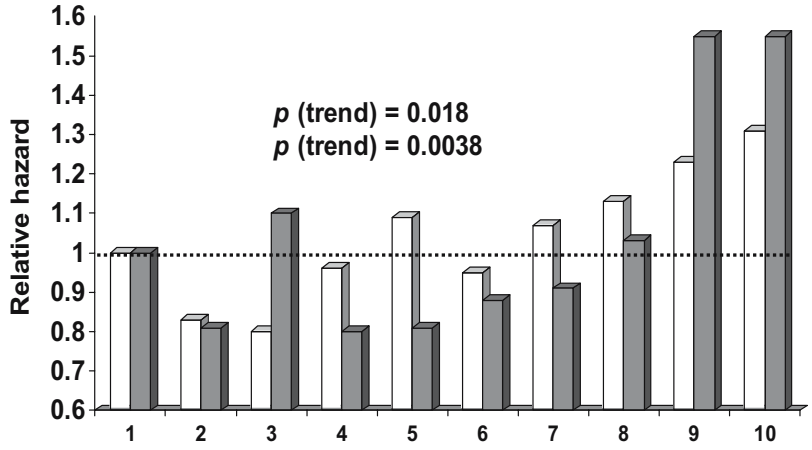

\begin{tabular}{lcccccccccc} 
GHb decile ranges & $\mathbf{1}$ & $\mathbf{2}$ & $\mathbf{3}$ & $\mathbf{4}$ & $\mathbf{5}$ & $\mathbf{6}$ & $\mathbf{7}$ & $\mathbf{8}$ & $\mathbf{9}$ & $\mathbf{1 0}$ \\
\hline Baseline & $<5.2$ & 5.2 & 5.9 & 6.4 & 6.8 & 7.3 & 7.7 & 8.2 & 8.9 & $\geq 9.9$ \\
Updated & $<5.8$ & 5.8 & 6.3 & 6.7 & 7.0 & 7.4 & 7.8 & 8.2 & 8.6 & $\geq 9.4$
\end{tabular}

Fig. 1 The progressive relationship between baseline (white bars) and updated (shaded bars) GHb levels (divided into deciles) and the age- and sex-adjusted relative hazard of the primary outcome (a),

\section{Discussion}

In this epidemiological analysis of the HOPE study data collected in individuals with diabetes, the $\mathrm{GHb}$ value was an independent risk factor for a broad range of outcomes, including CV events, heart failure, death and overt nephropathy. A very similar relationship between fasting plasma glucose and outcomes was also noted in the group that included both diabetic and non-diabetic individuals. In this hospitalisation for heart failure (b), overt nephropathy (c) and total mortality (d). The lower limits of the ranges for each decile are indicated below the figure.

latter group, the relationship between fasting plasma glucose and CV events was maintained even after accounting for the presence or absence of diabetes.

The progressive nature of the relationship between the indices of glycaemia ( $\mathrm{GHb}$ and fasting plasma glucose) and outcomes, and the observation that fasting plasma glucose is a risk factor for $\mathrm{CV}$ events even after statistically accounting for the presence of diabetes, support the conclusion that it is the degree of hyperglycaemia, rather than
Table 2 Relationship between updated $\mathrm{GHb}$ and events

Updated GHb levels were calculated as the mean of all of the available measurements for each individual during the entire follow-up period.

$C H F$ congestive heart failure

${ }^{a}$ Relative risk per $1 \%$ increase in $\mathrm{GHb}$

\begin{tabular}{llclc}
\hline Event & $\begin{array}{l}\text { Model adjusted for age, sex, } \\
\text { diabetes duration and ramipril }\end{array}$ & $\begin{array}{l}\text { Model adjusted for age, sex, diabetes duration, } \\
\text { systolic BP, diastolic BP, WHR, } \\
\text { hyperlipidaemia and ramipril }\end{array}$ \\
\cline { 2 - 3 } & $\begin{array}{llll}\mathrm{RR}^{\mathrm{a}}(95 \% \mathrm{CI}) \\
\mathrm{RR}^{\mathrm{a}}(95 \% \mathrm{CI})\end{array}$ & $p$ value \\
\hline Primary outcome & $1.07(1.02-1.13)$ & 0.010 & $1.07(1.01-1.13)$ & 0.014 \\
CHF hospitalisation & $1.20(1.08-1.33)$ & 0.0005 & $1.20(1.08-1.33)$ & 0.0008 \\
Death & $1.13(1.06-1.20)$ & 0.0001 & $1.12(1.05-1.19)$ & 0.0004 \\
Overt nephropathy & $1.27(1.18-1.37)$ & $<0.0001$ & $1.26(1.17-1.36)$ & $<0.0001$ \\
\hline
\end{tabular}


a

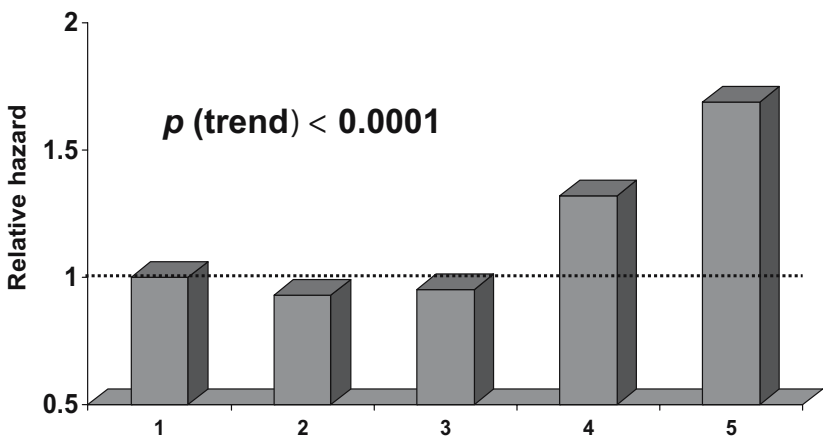

C

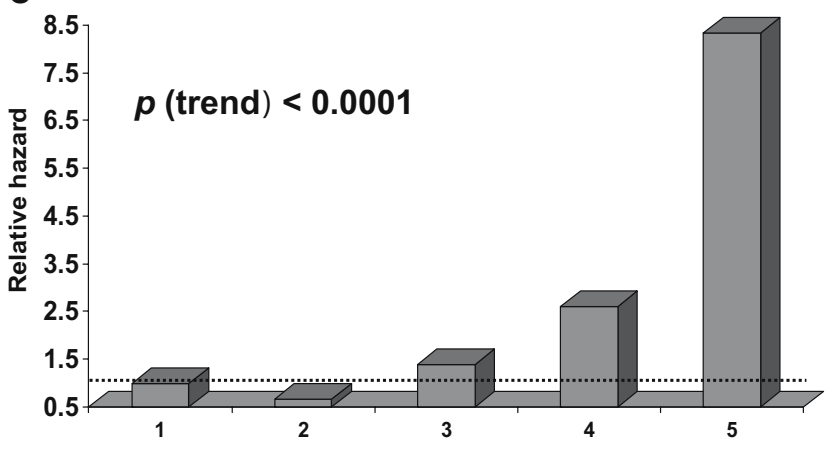

b

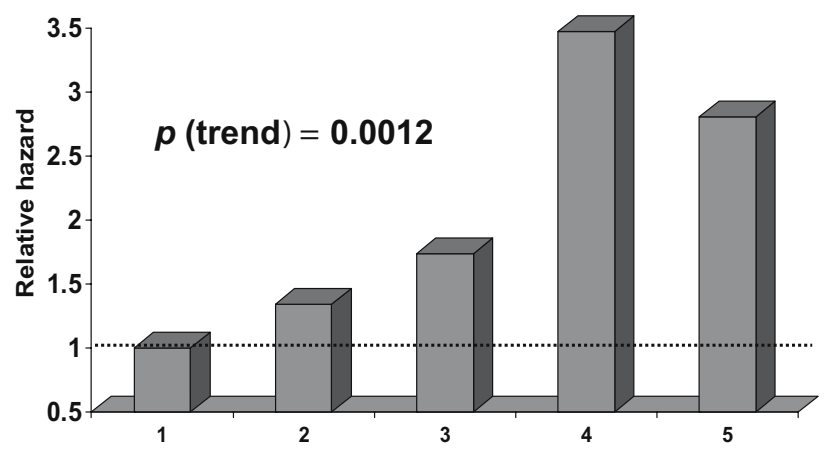

d

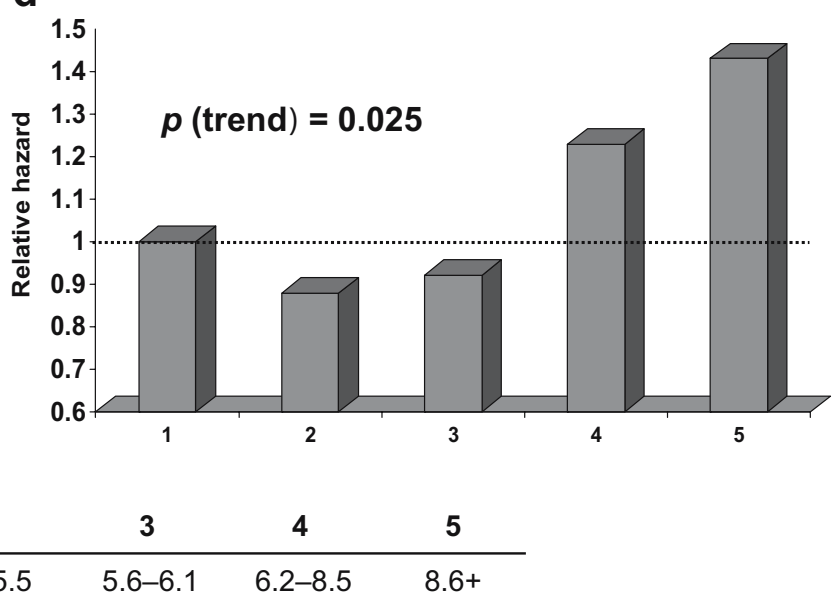

Fig. 2 The progressive relationship between baseline fasting plasma glucose (FPG; divided into quintiles) and the age- and sex-adjusted relative hazard of the primary outcome (a), hospitalisation for heart failure (b), overt nephropathy (c) and total mortality (d)

the presence or absence of diabetes as such, that is related to future $\mathrm{CV}$ outcomes. As the relationship between outcomes and the indices of glycaemia was not attenuated after adjusting for blood pressure, abdominal obesity or hyperlipidaemia, these other risk factors are insufficient to explain all of the risk associated with dysglycaemia. Of note, however, it is possible that the relationship would have been attenuated to some degree if the definition of hyerlipidaemia had included hypertriglyceridaemia. The fact that this was not observed with respect to the relationship between fasting plasma glucose and events ar- gues against this possibility. Thus, these analyses support the hypothesis that management of traditional risk factors may not eliminate the risk related to glucose. Similarly, accounting for ranpdomisation to ramipril did not attenuate the relationship of clinical outcomes with either $\mathrm{GHb}$ or fasting plasma glucose. Thus, the proven $\mathrm{CV}$ and renal benefits of ramipril $[14,16,18]$ cannot be completely explained by its possible effect on glucose levels.

These data are limited by the fact that $\mathrm{GHb}$ levels were not assessed centrally or by the same methodology, and may not all have been determined using assays standard-

Table 3 Relationship between fasting plasma glucose and events

\begin{tabular}{|c|c|c|c|c|c|c|}
\hline \multirow[t]{2}{*}{ Event } & \multicolumn{2}{|c|}{$\begin{array}{l}\text { Model adjusted for age } \\
\text { and sex }\end{array}$} & \multicolumn{2}{|c|}{$\begin{array}{l}\text { Model adjusted for age, sex, systolic BP, } \\
\text { diastolic BP, WHR, hyperlipidaemia and } \\
\text { ramipril }\end{array}$} & \multicolumn{2}{|c|}{$\begin{array}{l}\text { Model adjusted for age, sex, systolic BP, } \\
\text { diastolic BP, WHR, cholesterol: HDL, } \\
\text { triglyceride and ramipril }\end{array}$} \\
\hline & $\mathrm{RR}^{\mathrm{a}}(95 \% \mathrm{CI})$ & $p$ value & $\mathrm{RR}^{\mathrm{a}}(95 \% \mathrm{CI})$ & $p$ value & $\mathrm{RR}^{\mathrm{a}}(95 \% \mathrm{CI})$ & $p$ value \\
\hline Primary outcome & $1.10(1.06-1.14)$ & $<0.0001$ & $1.09(1.05-1.13)$ & $<0.0001$ & $1.09(1.05-1.14)$ & $<0.0001$ \\
\hline CHF hospitalisation & $1.18(1.09-1.28)$ & $<0.0001$ & $1.16(1.06-1.13)$ & 0.0007 & $1.14(1.04-1.24)$ & 0.0043 \\
\hline Death & $1.08(1.03-1.13)$ & 0.0017 & $1.06(1.01-1.12)$ & 0.0166 & $1.07(1.01-1.12)$ & 0.014 \\
\hline Overt nephropathy & $1.36(1.26-1.47)$ & $<0.0001$ & $1.34(1.23-1.45)$ & $<0.0001$ & $1.30(1.19-1.41)$ & $<0.0001$ \\
\hline
\end{tabular}

$\mathrm{CHF}$ congestive heart failure

${ }^{a}$ Relative risk per 0.15 -unit increase in log fasting plasma glucose $(\sim 1 \mathrm{mmol} / 1$ increase in fasting plasma glucose $)$ 
ised to international reference assays. They are also limited by the fact that GHb levels were only measured in diabetic participants. Thus, these data do not provide information regarding the relationship between $\mathrm{GHb}$ and outcomes in non-diabetic individuals. Moreover, glucose tolerance tests were not performed in participants to definitively determine their diabetes status or degree of hyperglycaemia, and fasting plasma glucose was only measured in a subset of diabetic individuals. Clearly, these additional data, as well as data on other CV risk factors, would have added precision and confidence to the risk estimates in both diabetic and non-diabetic individuals, and would have enabled an analysis of the relative importance of the $\mathrm{GHb}$ level, as compared with the glucose level, as a predictor of events. Nevertheless, the fact that strong associations were seen despite this heterogeneity and possibility of misclassification suggests that these findings are robust. Indeed, the observation of a stronger link between outcomes and updated $\mathrm{GHb}$ (compared with the baseline $\mathrm{GHb}$ ) is consistent with the well-known phenomenon of regression-dilution bias [19] and suggests that a stronger association between fasting plasma glucose and outcomes would have been detected if updated fasting plasma glucose levels were available. Thus, it is likely that these findings are underestimates of the true relationship between indices of glycaemia and key clinical outcomes.

These prospective observations from the HOPE study add to a growing body of epidemiological data in both diabetic and non-diabetic individuals [11, 12, 20-23], and further support the possibility that glucose lowering may reduce CV events. They also strongly support the need for large randomised, controlled clinical trials designed to confirm or refute preliminary suggestions that glucose lowering may reduce $\mathrm{CV}$ events in ambulatory people with newly diagnosed diabetes [24], established diabetes [25] or IGT [26, 27].

Acknowledgements This work was funded by grants from the Medical Research Council of Canada (Grant numbers MT12790 and UI12362), Aventis, Astra Zeneca, the Natural Source Vitamin E Association, NEGMA and King Pharmaceuticals.

Duality of Interest

H. C. Gerstein has received consulting fees, speaker's fees and grants from the following companies with drugs that lower glucose levels: Aventis, Novo Nordisk, Eli Lilly and GSK. G. R. Dagenais has received speaker's fees from Aventis.

\section{References}

1. Gerstein HC, Malmberg K, Capes S, Yusuf S (2001) Cardiovascular diseases. In: Gerstein HC, Haynes RB (eds) Evidencebased diabetes care. BC Decker, Hamilton, pp 488-514

2. Laakso M (1999) Hyperglycemia and cardiovascular disease in type 2 diabetes. Diabetes 48:937-942

3. Brownlee M (2001) Biochemistry and molecular cell biology of diabetic complications. Nature 414:813-820

4. Bonora E, Formentini G, Calcaterra F et al (2002) HOMAestimated insulin resistance is an independent predictor of cardiovascular disease in type 2 diabetic subjects: prospective data from the Verona Diabetes Complications Study. Diabetes Care 25:1135-1141
5. Baron AD (2002) Insulin resistance and vascular function. J Diabetes Its Complicat 16:92-102

6. Porte D Jr, Kahn SE (2001) Beta-cell dysfunction and failure in type 2 diabetes: potential mechanisms. Diabetes 50(Suppl 1): S160-S163

7. Lakka HM, Laaksonen DE, Lakka TA et al (2002) The metabolic syndrome and total and cardiovascular disease mortality in middle-aged men. JAMA 288:2709-2716

8. DECODE Study Group, European Diabetes Epidemiology Group (2003) Is the current definition for diabetes relevant to mortality risk from all causes and cardiovascular and noncardiovascular diseases? Diabetes Care 26:688-696

9. Coutinho M, Gerstein HC, Wang Y, Yusuf S (1999) The relationship between glucose and incident cardiovascular events. A metaregression analysis of published data from 20 studies of 95,783 individuals followed for 12.4 years. Diabetes Care 22: 233-240

10. Gerstein HC, Anand S, Yi QL et al (2003) The relationship between dysglycemia and atherosclerosis in South Asian, Chinese, and European individuals in Canada: a randomly sampled cross-sectional study. Diabetes Care 26:144-149

11. Stratton IM, Adler AI, Neil HA et al (2000) Association of glycaemia with macrovascular and microvascular complications of type 2 diabetes (UKPDS 35): prospective observational study. BMJ 321:405-412

12. Khaw KT, Wareham N, Luben R et al (2001) Glycated haemoglobin, diabetes, and mortality in men in Norfolk cohort of European Prospective Investigation of Cancer and Nutrition (EPIC-Norfolk). BMJ 322:15-18

13. Heine RJ, Dekker JM (2002) Beyond postprandial hyperglycaemia: metabolic factors associated with cardiovascular disease. Diabetologia 45:461-475

14. HOPE Study Investigators (2000) Effects of an angiotensinconverting-enzyme inhibitor, ramipril, on cardiovascular events in high-risk patients. N Engl J Med 342:145-153

15. Gerstein HC, Bosch J, Pogue J et al (1996) Rationale and design of a large study to evaluate the renal and cardiovascular effects of an ACE inhibitor and vitamin $\mathrm{E}$ in high-risk patients with diabetes. The MICRO-HOPE study. Diabetes Care 19:1225-1228

16. Heart Outcome Prevention Evaluation (HOPE) Study Investigators (2000) Effects of ramipril on cardiovascular and microvascular outcomes in people with diabetes mellitus: results of the HOPE study and MICRO-HOPE substudy. Lancet 355: 253-259

17. HOPE Study Investigators (1996) The HOPE (Heart Outcomes Prevention Evaluations) Study: the design of a large, simple randomized trial of an angiotensin converting enzyme inhibitor (ramipril) and vitamin $\mathrm{E}$ in patients at high risk of cardiovascular events. Can J Cardiol 12:127-137

18. Mann JF, Gerstein HC, Yi QL et al (2003) Development of renal disease in people at high cardiovascular risk: results of the HOPE randomized study. J Am Soc Nephrol 14:641-647

19. Clarke R, Shipley M, Lewington S et al (1999) Underestimation of risk associations due to regression dilution in long-term follow-up of prospective studies. Am J Epidemiol 150:341-353

20. Selvin E, Marinopoulos S, Berkenblit G et al (2004) Metaanalysis: glycosylated hemoglobin and cardiovascular disease in diabetes mellitus. Ann Intern Med 141:421-431

21. Gerstein HC, Capes SE (2002) Dysglycemia: a key cardiovascular risk factor. Semin Vasc Med 2:165-174

22. Khaw KT, Wareham N, Bingham S, Luben R, Welch A, Day N (2004) Association of hemoglobin A1c with cardiovascular disease and mortality in adults: the European prospective investigation into cancer in Norfolk. Ann Intern Med 141:413420

23. Gerstein HC (2004) Glycosylated hemoglobin: finally ready for prime time as a cardiovascular risk factor. Ann Intern Med 141:475-476 
24. UK Prospective Diabetes Study (UKPDS) Group (1998) Intensive blood-glucose control with sulphonylureas or insulin compared with conventional treatment and risk of complications in patients with type 2 diabetes (UKPDS 33). Lancet 352:837-853

25. Ohkubo Y, Kishikawa H, Araki E et al (1995) Intensive insulin therapy prevents the progression of diabetic microvascular complications in Japanese patients with non-insulin-dependent diabetes mellitus: a randomized prospective 6-year study. Diab Res Clin Pract 28:103-117
26. Chiasson JL, Josse RG, Gomis R, Hanefeld M, Karasik A, Laakso M (2003) Acarbose treatment and the risk of cardiovascular disease and hypertension in patients with impaired glucose tolerance: the STOP-NIDDM trial. JAMA 290:486-494

27. Knowler WC, Sartor G, Melander A, Schersten B (1997) Glucose tolerance and mortality, including a substudy of tolbutamide treatment. Diabetologia 40:680-686 